\title{
The Analytical Performances of Four Different Glycated Hemoglobin Methods
}

\author{
Genc S*, Gurdol F, Kanmaz-Ozer M , Ince N , Ozcelik F and Omer B \\ Istanbul University, Istanbul Faculty of Medicine, Department of Biochemistry, Capa, Istanbul, Turkey
}

\begin{abstract}
Objectives: The analytical performances of the Sebia capillary electrophoresis (CE), Roche turbidimetric inhibition immunoassay (TINIA), Tosoh G8 cation-exchange high-performance liquid chromatography (HPLC) and Premier boronate affinity chromatography methods were evaluated. Capillary electrophoresis (CE) was accepted as a comparative method.

Design and Methods: This study comprised randomly chosen 224 whole blood samples from the diabetic and non-diabetic patients. HbA1c level was quantified using four methods as follows: Roche TINIA, Premier Hb9210 boronate affinity chromatography, Tosoh G8 cation-exchange HPLC and Sebia CE. The analytical performances of the methods were evaluated with imprecion, bias estimation and comparison studies.

Results: The results of all precision studies $\mathrm{CV} \%$ were under $2.0 \%$. The accepted goals for imprecision are $2.8 \%$ (IFCC) and $<2.0 \%$ (NGSP). Analysis using Spearman test showed good correlation between CE and all three evaluated methods $(r=0.99, p=0.001 ; r=0.98, p=0.001$; and $r=0.98, p=0.001$, respectively). The comparison of the methods with CE was performed using Deming Regression analysis and revealed good agreement between CE and all methods. Although the HPLC method showed a linear relation with CE, it differed significantly from the comparative method because of its confidence interval did not contain 0 .
\end{abstract}

Conclusion: All methods revealed acceptable precision and good accuracy. TINIA and boronate affinity chromatography methods showed good agreement and correlation with the comparative method (CE), whereas a significant difference was obtained between the mean levels of HPLC and CE.

Keywords: Hemoglobin A1c; Electrophoresis; Capillary; Chromatography; High-performance liquid chromatography; Boronate affinity

\section{Introduction}

Hemoglobin Alc (HbAlc) assay is accepted as the most useful marker to determine the long-term glycemic control of diabetic patients. This marker has also been recommended for the diagnosis of diabetes mellitus when $\mathrm{HbAlc}$ levels are above $48 \mathrm{mmol} / \mathrm{mol}(6.5 \%)$ [1]. The relation between $\mathrm{HbAlc}$ levels and diabetic complications has been evaluated by the studies of Diabetes Control and Complications Trial Research Group (DCCT). According to their observations, a $1 \%$ decrement in $\mathrm{HbA1c}$ level complies with an approximate $30 \%$ reduction in developing risk of diabetic complications [2].

Accurate $\mathrm{HbAlc}$ results are essential for monitoring and appropriate treatment of diabetic patients. Nowadays, the methods for measuring $\mathrm{HbAlc}$ are classified into 3 groups: ion-exchange chromatography electrophoresis and isoelectric focusing which based on charge differences between glycated $\mathrm{Hb}$ and non-glycated $\mathrm{Hb}$ [2], affinity chromatography and immunoassay which based on structural differences of glycogroups on hemoglobin $[3,4]$ and photometry and electrospray mass spectrometry in which separation is based on chemical reactivity. Many factors may interfere with the HbAlc results causing falsely high or low results depending on the assay methods. While cation exchange methods are not affected from the interference by Schiff base or carbamylated haemoglobin, it may be influenced from hemoglobin variants. Similar interference may also be observed in electrophoretic methods. Boronate affinity measures total glycated hemoglobin consisting of $\mathrm{HbAlc}$ and other $\mathrm{Hb}$ adducts regardless of charge, and provides very good precision and accuracy [5]. Capillary electrophoresis (CE) and electrospray mass spectrometry were introduced as the candidate reference methods by International Federation of Clinical Chemistry (IFCC) in 2001. This method is based on enzymatic cleavage of $\mathrm{N}$-terminal hexapeptides from the $\beta$-chain, then glycated and non-glycated hexapeptides are measured by HPLC/ mass spectrometry or HPLC/capillary electrophoresis. Interferences caused by the $\mathrm{Hb}$ variants and derivatives in the capillary electrophoresis are less seen than those in the ion-exchange chromatographic methods [6]. The reported stability, reproducibility, and repeatability of this analytical system were very good [5].

In the Clinical Laboratory of Istanbul Faculty of Medicine which has a very high workflow, an establishment of the accurate, timely and cost effective method with a high precision is essential. Therefore, attempts have been made to evaluate the analytical performances of Roche Tinaquant $3^{\text {rd }}$ generation $\mathrm{HbAlc}$ assays based on immunoturbidimetry, Tosoh G8 cation-exchange HPLC and Premier boronate affinity chromatography methods. The Sebia capillary electrophoresis was used as the comparative method in our study.

\section{Materials and Methods}

\section{Subjects and samples}

This study comprised 224 whole blood samples with a median age of 51 (Range 20-83) randomly chosen from the subjects who were applied to Clinical Biochemistry Laboratory of Istanbul Faculty of Medicine between June to July 2011, for either routine testing or the

*Corresponding author: Sema Genc, Istanbul University, Istanbul Faculty of Medicine, Department of Biochemistry, Capa, Istanbul, Turkey, Tel: +90 212 6214756; E-mail: nsgenc@hotmail.com

Received June 06, 2014; Accepted June 26, 2014; Published June 28, 2014

Citation: Genc S, Gurdol F, Kanmaz-Ozer M, Ince N, Ozcelik F, et al. (2014) The Analytical Performances of Four Different Glycated Hemoglobin Methods. Med chem 4: 501-505. doi:10.4172/2161-0444.1000185

Copyright: $\odot 2014$ Genc S, et al. This is an open-access article distributed under the terms of the Creative Commons Attribution License, which permits unrestricted use, distribution, and reproduction in any medium, provided the original author and source are credited. 
control of the diabetic status. No further selection criteria were used. $\mathrm{HbA} 1 \mathrm{c}$ values ranged from 21.3 to $122 \mathrm{mmol} / \mathrm{mol}$ (4.1\% to $13.3 \%)$. Of the 224 subjects, 115 (51.3\%) were women.

Blood samples were obtained through venipuncture into $2.0 \mathrm{~mL}$ BD Vacutainer ${ }^{\circledR}$, Hemogard tubes with $\mathrm{K}_{2}$-EDTA (Becton Dickinson, Plymouth, UK) and leftover samples were used to measure the HbAlc levels. All samples were kept $+4^{\circ} \mathrm{C}$ until studied. HbAlc levels were measured with four different methods and assays were completed within four hours following blood sampling. This study was approved by the Ethics Committee of Istanbul University and informed consent forms were obtained from each subject prior to the study (B.08.06. YOK.2.İ.Ü. E.50.0.05.00/23).

\section{HbA1c methods}

$\mathrm{HbA1c}$ levels from the samples of 224 subjects were determined simultaneously using four commercially available methods. These included the turbidimetric inhibition immunoassay (TINIA) by using Roche E170 autoanalyzer (Roche, Mannheim, Germany), boronate affinity chromatography by Premier Hb 9210 (Trinity Biotech, Wicklow, Ireland), cation-exchange high-performance liquid chromatography (HPLC) by Tosoh G8 (Bioscience, San Francisco, USA), and capillary zone electrophoresis with automated Sebia capillary electrophoresis (Sebia, Norcross, USA). All these methods were carried out according to the manufacturer's instructions and certified by the National Glycohemoglobin Standardization Program (NGSP). Sebia capillary zone electrophoresis was used as the comparative method.

\section{Precision studies}

Whole blood sample pools which comprised twenty patients' samples at low (33.3 mmol/mol, $5.2 \pm 0.05 \%)$; and high levels $(102.2$ $\mathrm{mmol} / \mathrm{mol}, 11.5 \pm 0.06 \%$ ) were used to determine the assay precision. The two-level pools were studied 20 times for within-run and 20 times for between-day precisions on consecutive days, followed by the calculation of variation coefficient (CV\%) and standard deviations (SDs).

\section{Statistical analysis}

The coefficient of variation $(\mathrm{CV})$ was expressed as the ratio of standard deviation to mean. Statistical analyses were performed using SPSS 15.0 software (SPSS Inc. Chicago, IL, USA). The Spearman correlation analyses were applied for the initial comparison of the methods. Two stage linear regression analysis, Bland Altman and Deming Regression analysis were performed for bias estimation and the method comparisons. These analyses were done by using MedCalc 12.7.2 software (Ostend, Belgium). $\mathrm{P}<0.05$ was considered statistically significant.

\section{Results}

The findings of precision study carried on the sample pools with low and high levels of HbAlc are shown in Table 1. For high pool (mean value: $102.2 \mathrm{mmol} / \mathrm{mol}, 11.5 \pm 0.06 \%$ ); TINIA assay had withinrun $\mathrm{CV} 0.7 \%$ and between-run $\mathrm{CV} 0.6 \%$, cation-exchange HPLC method had within-run CV $1.8 \%$ and between-run CV 2.0\%, and affinity chromatography had within-run CV $0.4 \%$ and between-run CV $0.1 \%$. Capillary electrophoresis revealed within-run CV $0.8 \%$ and between-run CV 0.8\%. For the low control (mean value:33. 3mmol/ mol,5.2 $\pm 0.05 \%$ ); TINIA assay had within-run CV $1.6 \%$ and betweenrun CV 1.6\%, HPLC method had within-run CV 1.1\% and betweenrun CV $1.8 \%$, and affinity chromatography had within-run CV $0.5 \%$ and between-run CV $0.2 \%$, capillary electrophoresis had within-run CV 1.1\% and between-run CV 0.3\%. Overall, the results of all precision studies (within-run and between-days) were well below 2.0\% CV. The accepted goals for imprecision are $2.8 \%$ (IFCC) and $<2.0 \%$ (NGSP) $[7,8]$.

Initial comparison results of four methods using Spearman test showed good correlation between capillary electrophoresis and cationexchange HPLC, boronate affinity and TINIA methods $(\mathrm{r}=0.99, \mathrm{r}=0.98$, $\mathrm{r}=0.98$, respectively; $\mathrm{p}=0.001$ ).

The Bland Altman plots of differences between the capillary electrophoresis and other methods are shown in Figure $1(\mathrm{a}, \mathrm{b}, \mathrm{c})$. The mean difference $( \pm 2 \mathrm{SD})$ was $-0.25 \%(-0.67-0.17)$ for TINIA, $-0.03 \%$ $(-0.42-0.35)$ for boronate affinity and, $0.07(-0.26-0.40)$ for cationexchange HPLC method. The mean biases which are measured between the methods were lower than $2.0 \%$ as specified by IFCC $(<1.1 \%$ for NGSP) $[7,8]$.

Data of method comparisons obtained by a set of whole blood samples $(n=224)$ are summarized in Figure $2(a, b, c)$, and Table 2. When the Deming regression analysis was evaluated between capillary electrophoresis and other methods, good agreement was observed between capillary electrophoresis and TINIA $(y=1.03 x+0.016$; CI $=-$ 0.14 to $0.1821, r=0.9925)$ and also between capillary electrophoresis and boronate affinity chromatography $(\mathrm{y}=1.0 \mathrm{x}+1,11855, \mathrm{CI}=0,0000$ to $0,2981, r=0.9974)$. All values obtained were found to lie in the $95 \%$ confidence interval. Although the HPLC method showed a linear relation with $\mathrm{CE}(\mathrm{y}=1,063 \mathrm{x}-0,52+, \mathrm{CI}=-0.6338-(-0.4625, \mathrm{r}=0.9934)$, a significant difference was obtained between the means of HPLC and comparative methods because of its confidence interval did not contain 0 .

\section{Discussion}

Overall precision and bias of the methods, the correlation with the reference method and interlaboratory agreement of the results are necessary steps in order to maintain optimum care of the patients and to provide the quality of clinical trials. In our study, the analytical performance of boronate affinity, cation-exchange HPLC and TINIA $\mathrm{HbA1c}$ methods were evaluated comparing with CE. The methods indicated a good precision and accuracy. The TINIA and boronate affinity showed good agreement with $\mathrm{CE}$ by showing a narrow dispersion around the regression lines. Although the HPLC method showed a linear relation with $\mathrm{CE}$, a significant difference was obtained between the mean levels of HPLC and CE. Because its confidence interval did not contain 0 (CI; 0.63 to -0.4625 ).

The precision studies revealed within-run CVs lower than $1.7 \%$ and between-run CVs lower than $2.0 \%$. This findings are in good agreement with the goals of NGSP $(<2.0 \%)$ and IFCC $(<2.8 \%)$ [8].

A previous study evaluating the analytical performances of $\mathrm{CE}$ reported intra- and inter-assay CVs were $1.62 \%$ and $1.45 \%$, and these findings are in good agreement with our findings, also good agreement

\begin{tabular}{|c|c|c|c|c|}
\hline & \multicolumn{2}{|c|}{ High pool } & \multicolumn{2}{|c|}{ Low pool } \\
\hline Methods & $\begin{array}{c}\text { Within- } \\
\text { run } \\
\text { CV\% }\end{array}$ & $\begin{array}{c}\text { Between- } \\
\text { day CV\% }\end{array}$ & $\begin{array}{c}\text { Within-run } \\
\text { CV\% }\end{array}$ & $\begin{array}{c}\text { Between-day } \\
\text { CV\% }\end{array}$ \\
\hline TINIA & 0.7 & 0.6 & 1.6 & 1.6 \\
\hline Cation-exchange HPLC & 1.8 & 2.0 & 1.1 & 1.8 \\
\hline & 0.4 & 0.1 & 0.5 & 0.2 \\
\hline Capillary electrophoresis & 0.8 & 0.8 & 1.1 & 0.3 \\
\hline
\end{tabular}

Table 1: Within-run and between day coefficients of variation (CV\%) of $\mathrm{HbA} 1 \mathrm{c}$ levels measured by the four methods using whole blood sample pool at low (33. 3 $\mathrm{mmol} / \mathrm{mol}, 5.2 \pm 0.05 \%)$ and high level (102.2 $\mathrm{mmol} / \mathrm{mol}, 11.5 \pm 0.06 \%)$. 
(a)

(b)
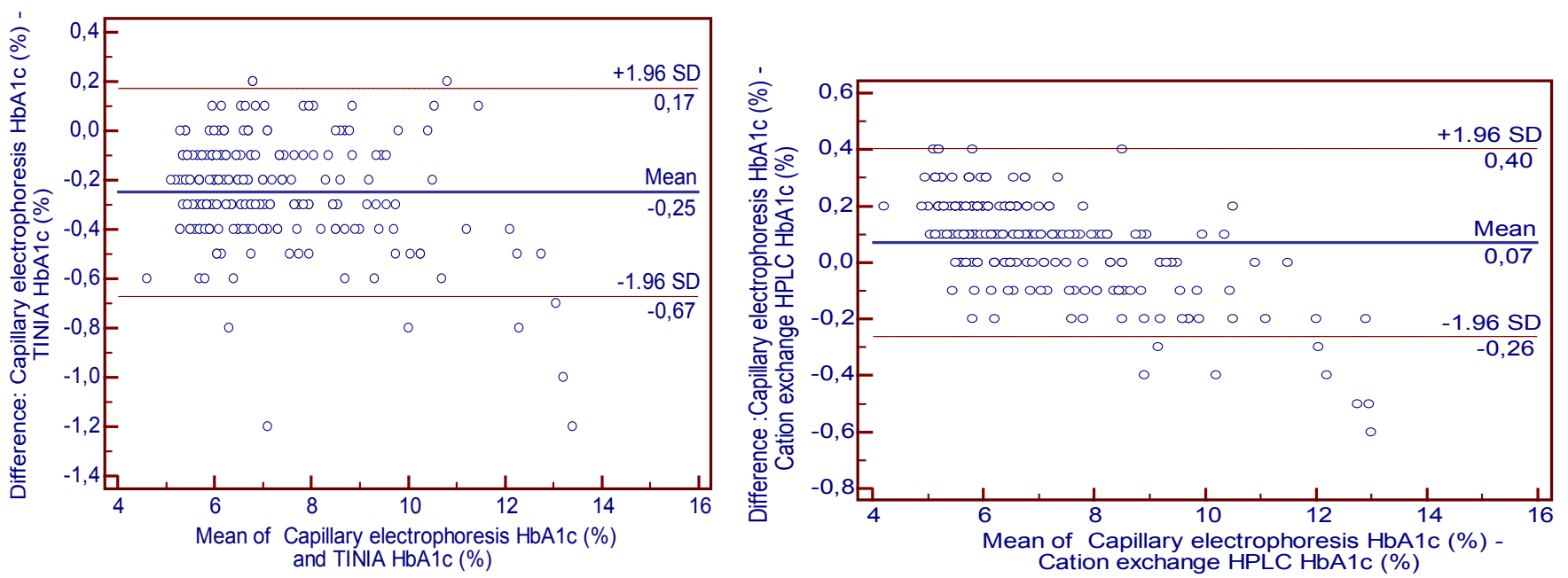

(c)

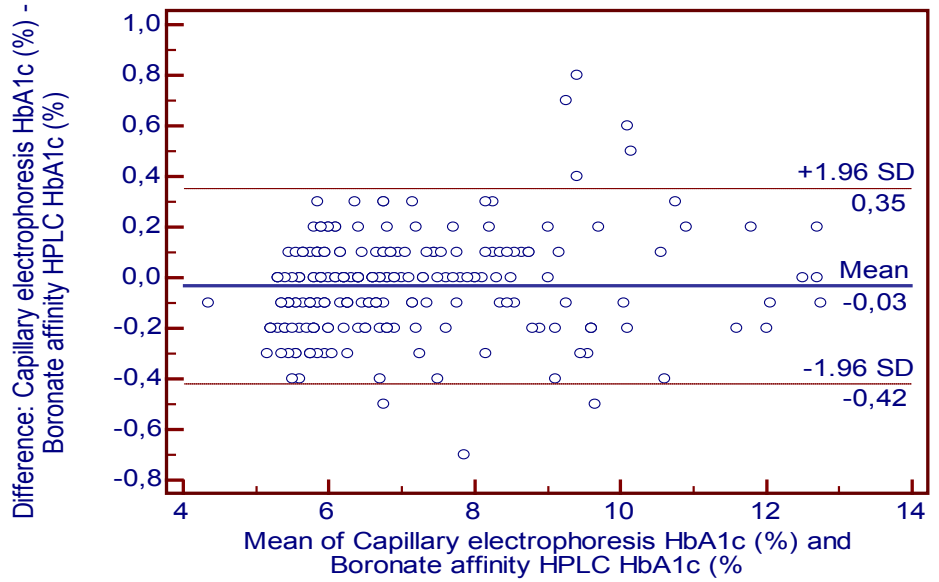

Figure 1: Bland-Altman plot of difference in HbA1c levels analyzed by 1a) TINIA and Capillary electrophoresis. 1b) Cation Exchange HPLC and Capillary electrophoresis. 1c) Boronate affinity HPLC and Capillary electrophoresis

was obtained between Variant II HPLC method and CE method with no interfering effect of fetal hemoglobin, labile HbAlc, and high urea concentration in this study [9]. However, another study, the CV\% of Variant II HPLC and Roche Integra 800 with TINIA were reported higher than $2.0 \%$ for low control and the bias \% for Variant II and Tosoh G8 were found $-4.9 \%$ and 3.9, respectively [10]. In our study, estimated mean difference of the methods from CE were found very small; $-0.25 \%$ $(-0.67-0.17)$ for TINIA, $-0.03 \%(-0.42-0.35)$ for boronate affinity and, $0.07 \%(-0.26-0.40)$ for cation- exchange HPLC method. Allowable bias for HbAlc was suggested by Rohlfing in 2008 as a $\leq \pm 1.5 \%$ desirable and a $\leq \pm 0.8 \%$ optimal [11]. The values obtained in our study were at desirable level. In our previous study included 2917 subjects, second generation TINIA assay was well associated with the HPLC by Arkray Adams HA-8160, mean bias was $0.19 \%$ [12]. In the study of Abadie et al. which included 80 patients with $\mathrm{HbS}$ or $\mathrm{HbC}$, the second generation TINIA assay exhibited a better agreement with HPLC method than first generation TINIA assay [13]. In another study, no interferences were seen due to the presence of $\mathrm{HbD}$ and $\mathrm{HbE}$ traits in the immunoassay, enzymatic, boronate affinity or capillary electrophoresis whereas a significant interference occurred in some ion-exchange methods [14].

In this study, four current methods for the HbAlc measurement were evaluated, and all methods revealed acceptable precision and good accuracy. TINIA and boronate affinity chromatography methods showed good agreement and correlation with the comparative method (CE), while a significant constant difference was obtained between the mean level of the HPLC and CE methods. The size and characteristics of our study population were not suitable for an investigation of possible interference of hemoglobin variants and various metabolites such as urea and triglycerides on HbAlc levels. Further studies by the interference analysis are needed to examine the effect of such factors on the glycated hemoglobin measurements. 
2a.
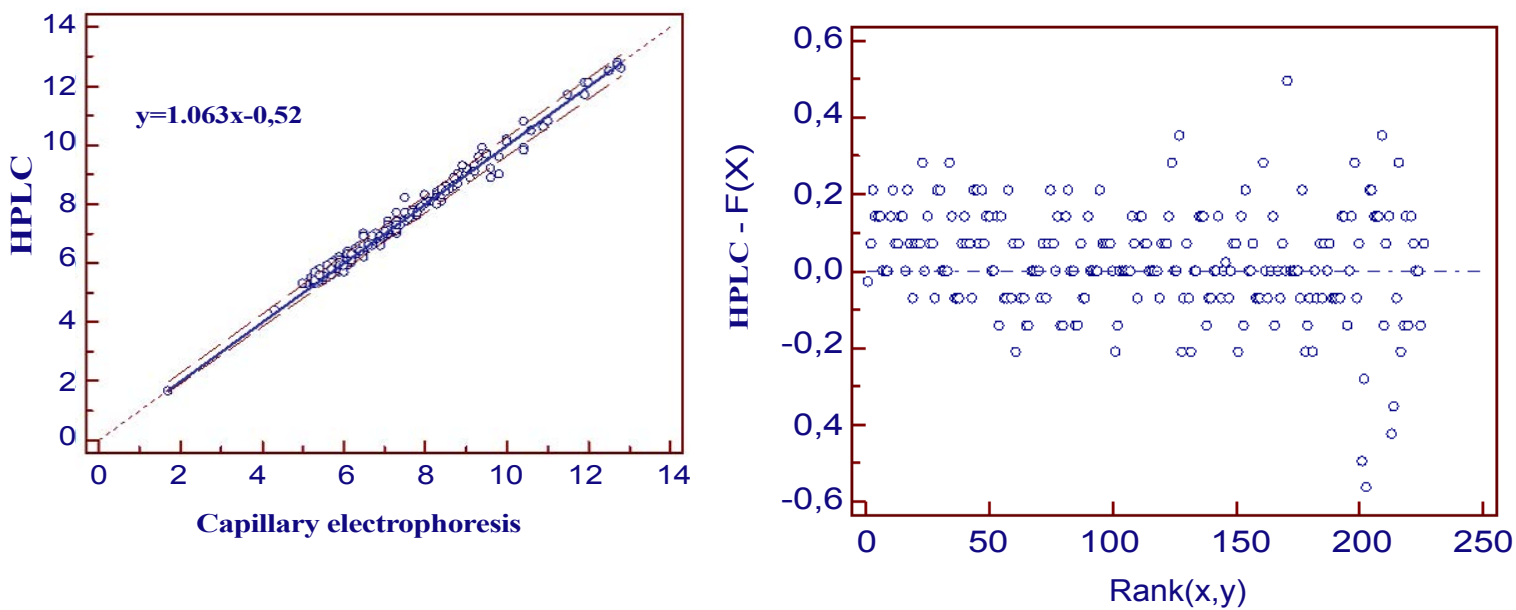

$2 b$.
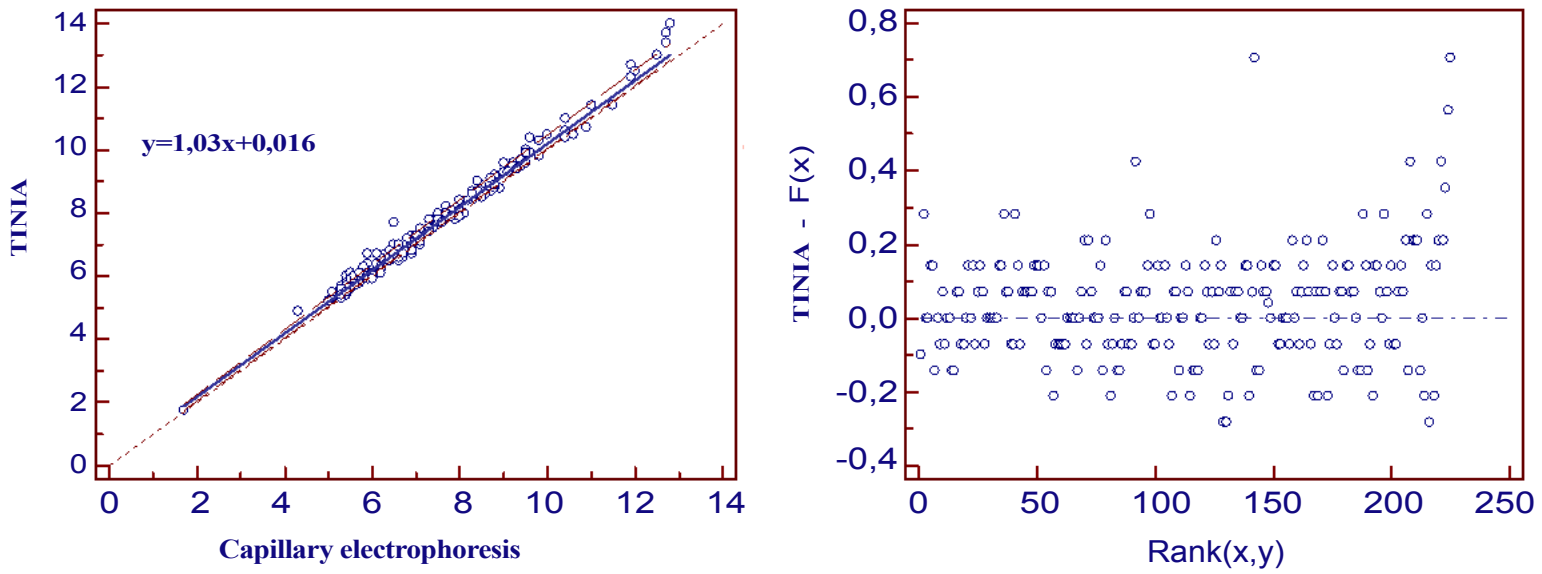

2c.
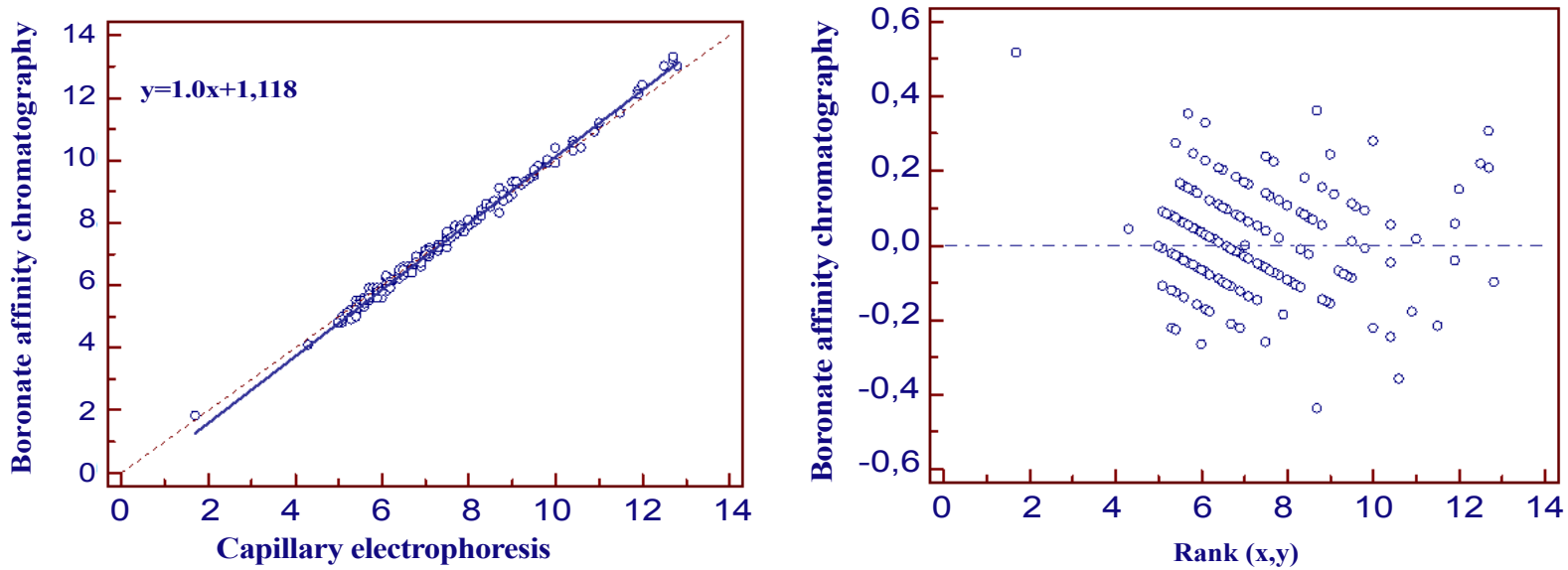

Figure 2: Comparison of the results of HbA1c methods 2a) TINIA vs Capillary electrophoresis. 2b) Boronate affinity HPLC vs Capillary electrophoresis 2c) Cation Exchange HPLC vs Capillary electrophoresis. 
Citation: Genc S, Gurdol F, Kanmaz-Ozer M, Ince N, Ozcelik F, et al. (2014) The Analytical Performances of Four Different Glycated Hemoglobin Methods. Med chem 4: 501-505. doi:10.4172/2161-0444.1000185

\begin{tabular}{|c|c|c|c|c|c|c|}
\hline Methods & Bias \% & Slope & Intercept & SE & $95 \mathbf{~ C l ~ \% ~}$ & $\mathbf{r}$ \\
\hline CE- TINIA & $\begin{array}{c}-0.25 \\
-0.67-0.17\end{array}$ & 1.03 & 0.016 & 0.089 & $-0.14-0.1821$ & 0.9925 \\
\hline CE-HPLC & $\begin{array}{c}0.07 \\
-0.26-0.40\end{array}$ & 1.063 & -0.52 & 0.048 & $-0.63-(-0.46)$ & 0.9934 \\
\hline $\begin{array}{c}\text { CE- Affinity } \\
\text { chromatography }\end{array}$ & $\begin{array}{c}-0.03 \\
-0.42-0.35\end{array}$ & 1.00 & 1.1185 & 0.065 & $0.0-0.29$ & 0.9974 \\
\hline
\end{tabular}

Table 2: Comparison of capillary electrophoresis with TINIA, boronate affinity chromatogram and cation-exchange HPLC method: Individual results for the method-comparison studies $(n=224)$.

\section{References}

1. Gillett MJ (2009) International Expert Committee report on the role of the A1c assay in the diagnosis of diabetes: Diabetes Care 2009; 32(7): 1327-1334. Clin Biochem Rev 30: 197-200.

2. Weykamp C, John WG, Mosca A (2009) A review of the challenge in measuring hemoglobin A1c. J Diabetes Sci Technol 3: 439-445.

3. Sacks DB (2012) Measurement of hemoglobin A(1c): a new twist on the path to harmony. Diabetes Care 35: 2674-2680.

4. Glad Working Group A1c Delegates WG, Mosca A, Branca MT, Carta M, Genna $M L$, et al. (2010) Recommendations for the implementation of international standardization of glycated hemoglobin in Italy. Clin Chem Lab Med 48: 623626.

5. Pundir CS, Chawla S (2014) Determination of glycated hemoglobin with special emphasis on biosensing methods. Anal Biochem 444: 47-56.

6. Jeppsson JO, Kobold U, Barr J, Finke A, Hoelzel W, et al. (2002) Approved IFCC reference method for the measurement of $\mathrm{HbA} 1 \mathrm{c}$ in human blood. Clin Chem Lab Med 40: 78-89.

7. Fraser CG, Hyltoft Petersen P, Libeer JC, Ricos C (1997) Proposals for setting generally applicable quality goals solely based on biology. Ann Clin Biochem $34: 8-12$.

8. NCCLS (2004) Evaluation of precision performance of quantitative measurement methods: approved guideline-second edition. NCCLS document EP5-A2. Wayne, PA: NCCLS.

9. Jaisson S, Leroy N, Meurice J, Guillard E, Gillery P (2012) First evaluation of Capillarys 2 Flex Piercing $\AA \circledast$ (Sebia) as a new analyzer for HbA1c assay by capillary electrophoresis. Clin Chem Lab Med 50: 1769-1775.

10. Woodworth A, Korpi-Steiner N, Miller JJ, Rao LV, Yundt-Pacheco J, et al. (2014) Utilization of Assay Performance Characteristics to Estimate Hemoglobin A1c Result Reliability. Clin Chem

11. Rohlfing CL, Connolly SM, England JD, Hanson SE, Moellering CM, et al (2008) The effect of elevated fetal hemoglobin on hemoglobin A1c results: five common hemoglobin A1c methods compared with the IFCC reference method. Am J Clin Pathol 129: 811-814.

12. Genc S, Omer B, Aycan-Ustyol E, Ince N, Bal F, et al. (2012) Evaluation of turbidimetric inhibition immunoassay (TINIA) and HPLC methods for glycated haemoglobin determination. J Clin Lab Anal 26: 481-485.

13. Abadie JM, Koelsch AA (2008) Performance of the Roche second generation hemoglobin A1c immunoassay in the presence of HB-S or HB-C traits. Ann Clin Lab Sci 38: 31-36.

14. Little RR, Rohlfing CL, Hanson S, Connolly S, Higgins T, et al. (2008) Effects of hemoglobin $(\mathrm{Hb}) \mathrm{E}$ and $\mathrm{HbD}$ traits on measurements of glycated $\mathrm{Hb}(\mathrm{HbA1c})$ by 23 methods. Clin Chem 54: 1277-1282. 